\title{
Protein regulation strategies of the mouse spleen in response to Babesia microti infection
}

\author{
Xiaomin Xue ${ }^{1 \dagger}$, Shuguang Ren ${ }^{2 \dagger}$, Xiaohong Yang ${ }^{3 \dagger}$, Abolfazl Masoudi ${ }^{1}$, Yuhong Hu ${ }^{1,4}$, Xiaoshuang Wang ${ }^{1}$, \\ Hongxia Li $i^{1}$, Xiaojing Zhang ${ }^{1}$, Minjing Wang ${ }^{1}$, Hui Wang ${ }^{1 *}$ and Jingze Liu ${ }^{1 *}$
}

\begin{abstract}
Background: Babesia is a protozoan parasite that infects red blood cells in some vertebrates. Some species of Babesia can induce zoonoses and cause considerable harm. As the largest immune organ in mammals, the spleen plays an important role in defending against Babesia infection. When infected with Babesia, the spleen is seriously injured but still actively initiates immunomodulatory responses.
\end{abstract}

Methods: To explore the molecular mechanisms underlying the immune regulation and self-repair of the spleen in response to infection, this study used data-independent acquisition (DIA) quantitative proteomics to analyse changes in expression levels of global proteins and in phosphorylation modification in spleen tissue after Babesia microti infection in mice.

Results: After mice were infected with B. microti, their spleens were seriously damaged. Using bioinformatics methods to analyse dynamic changes in a large number of proteins, we found that the spleen still initiated immune responses to combat the infection, with immune-related proteins playing an important role, including cathepsin $D$ (CTSD), interferon-induced protein 44 (IFI44), interleukin-2 enhancer-binding factor 2 (ILF2), interleukin enhancerbinding factor 3 (ILF3) and signal transducer and activator of transcription 5A (STAT5A). In addition, some proteins related to iron metabolism were also involved in the repair of the spleen after $B$. microti infection, including serotransferrin, lactoferrin, transferrin receptor protein 1 (TfR1) and glutamate-cysteine ligase (GCL). At the same time, the expression and phosphorylation of proteins related to the growth and development of the spleen also changed, including protein kinase C- $\delta$ (PKC- $\delta$ ), mitogen-activated protein kinase (MAPK) 3/1, growth factor receptor-bound protein 2 (Grb2) and P21-activated kinase 2 (PAK2).

Conclusions: Immune-related proteins, iron metabolism-related proteins and growth and development-related proteins play an important role in the regulation of spleen injury and maintenance of homeostasis. This study provides an important basis for the diagnosis and treatment of babesiosis.

Keywords: Babesia microti, Spleen, Quantitative proteomics, Phosphorylation, Immune

*Correspondence: whui1981@163.com; liujingze@hebtu.edu.cn

'Xiaomin Xue, Shuguang Ren and Xiaohong Yang contributed equally to this work

1 Hebei Key Laboratory of Animal Physiology, Biochemistry

and Molecular Biology, College of Life Sciences, Hebei Normal University, Shijiazhuang 050024, Hebei, People's Republic of China

Full list of author information is available at the end of the article

\section{Background}

Babesia is a blood parasitic protozoan [1]. Hosts infected with Babesia develop babesiosis. Babesia is mainly transmitted by ticks and sometimes through blood transfusion or pregnancy [2,3]. People with Babesia infection exhibit symptoms such as fever, anaemia and haemoglobinuria, while people with severe infections may suffer multiple organ damage [4]. The life cycle of Babesia microti involves two hosts, including some species of Ixodes and 
the white-footed mouse (Peromyscus leucopus), and $B$. microti can also sometimes parasitize humans $[5,6]$.

The spleen is the largest immune system organ in the body. It is very important for the clearance of parasites. People with splenic insufficiency or who have undergone splenectomy will experience more severe diseases after suffering from babesiosis [7]. Babesia infection results in severe spleen injury. However, the injured spleen will still actively initiate immunomodulatory responses during self-repair. The spleen contains a large number of B lymphocytes and macrophages and can also produce immunoglobulins and complement factors that exert immune functions [8]. Initiation and operation of these immunomodulatory functions and repair mechanisms of the spleen are achieved through coordination among many proteins. These proteins exert their functions through changes in their expression levels and post-translational modifications. To elucidate the molecular regulatory mechanisms of immune responses and self-repair exhibited by the spleen during different stages of Babesia infection, this study used data-independent acquisition (DIA) [9] quantitative proteomics to comprehensively analyse changes in expression levels and phosphorylation modifications of proteins in mouse spleen tissues during different stages of $B$. microti infection. To our knowledge, this is the first proteomics study on mammalian spleen after Babesia infection. This study showed that expression levels of immune-, iron metabolism- and growth and development-related proteins in mouse spleen tissues changed after Babesia infection. In addition, phosphorylation modifications of these proteins also changed. These study results may provide a theoretical basis for analyses of how the spleen perceives Babesia infection stress and resists Babesia infection and a theoretical basis for effective detection, diagnosis and treatment of babesiosis.

\section{Methods}

Dissection of mouse spleen and sample preparation

Babesia microti (ATCC PRA-99 ${ }^{\mathrm{TM}}$ ) was obtained from the Institute of Laboratory Animal Sciences, Chinese Academy of Medical Sciences. Female BALB/c mice were raised to 6 weeks of age, and then the mice received intraperitoneal injection of $150 \mu \mathrm{l}$ of $B$. microti-infected erythrocytes $\left(1.8 \times 10^{7}\right)$ [10]. After 5 days, 8 days, 11 days and 19 days, mice infected with B. microti were anaesthetized and killed. Blood was collected from the tail tip every day to create blood smears. After Giemsa staining, $B$. microti infection status was observed under a microscope, and the parasitaemia level was calculated. The spleen of each mouse was dissected for total protein and quantitative phosphorylation proteomics experiments. The spleens of four mice were used for the uninfected group and each infection period. Four biological repeats were carried out, and a total of 20 mice were used. Spleen tissue samples $\left(2 \mathrm{~mm}^{3}\right)$ were immediately placed in $4 \%$ glutaraldehyde fixative for storage and used for subsequent transmission electron microscope (TEM) analysis. The remaining tissues were rapidly frozen at $-80{ }^{\circ} \mathrm{C}$ for subsequent proteomics studies. All experimental procedures were approved by the Animal Ethics Committee of Hebei Normal University (no. 165031). The involved animal feeding and material collection procedures were all performed in the level 2 biosafety laboratory in The Fourth Hospital of Hebei Medical University.

\section{Preparation of TEM samples and observation}

Fresh spleen tissues were fixed in $4 \%$ glutaraldehyde (Alfa Aesar, Germany) phosphate buffer ( $\mathrm{pH} 7.4$ ) at $4{ }^{\circ} \mathrm{C}$ for more than $4 \mathrm{~h}$. After flushing with $0.1 \mathrm{M}$ of phosphate buffer ( $\mathrm{pH} 7.4)$, the tissues were fixed again in $1 \%$ buffered osmium tetroxide solution (SPI-CHEM, USA) for $2 \mathrm{~h}$. In the next stage, the samples were washed in phosphate buffer and dehydrated in an acetone series. Dehydrated tissues were embedded in epoxy resin (SPIVHEM, USA). Resin polymerization was conducted at $60{ }^{\circ} \mathrm{C}$ for $36 \mathrm{~h}$. The ultrathin sections $(50-60 \mathrm{~nm}$ ) were stained with uranyl acetate (Polyscience, USA) and citrate lead (Sigma Aldrich, USA). The ultrastructure was observed by TEM (Hitachi H7650, Japan).

\section{Protein extraction and digestion}

Spleen tissues from different periods were ground (1 M $\mathrm{pH}$ 6.8) in a mortar containing a protease inhibitor cocktail (Roche, Mannheim, Germany) and centrifuged $\left(4{ }^{\circ} \mathrm{C}\right.$, $12,000 \times g, 15 \mathrm{~min})$. The supernatant was collected, and Tris-saturated phenol ( $\mathrm{pH} 7.8)$ was added, followed by centrifugation $\left(4{ }^{\circ} \mathrm{C}, 12,000 \times g, 15 \mathrm{~min}\right)$. After removing the supernatant, an equal volume of $50 \mathrm{mM}$ Tris$\mathrm{HCl}(\mathrm{pH}$ 8.0) was added, followed by centrifugation $\left(4{ }^{\circ} \mathrm{C}, 12,000 \times g, 20 \mathrm{~min}\right)$. After removing the supernatant, $0.1 \mathrm{M}$ ammonium acetate was added to precipitate the protein at $-20{ }^{\circ} \mathrm{C}$ overnight. The mixture was centrifuged $\left(4{ }^{\circ} \mathrm{C}, 12,000 \times g, 20 \mathrm{~min}\right)$, the protein pellet was washed with methanol twice, and the extracted proteins were lyophilized and stored at $-80^{\circ} \mathrm{C}$. The protein samples were subjected to alkylation for cysteine carbamidomethylation. After the protein was digested with trypsin (1:20 $\mathrm{w} / \mathrm{w}$, Promega, USA), the peptides were desalted with $\mathrm{C} 18$ SPE $\left(\mathrm{CNW}^{\circledR}\right.$, China) according to the manufacturer's instructions. The concentrations of the peptides obtained after trypsin digestion were determined using a BCA Protein Assay kit (Pierce Biotechnology). 
After normalizing the concentrations of the samples, the enzyme efficiency was monitored by LC-MS [consists of a UPLC M-Class system (Waters, USA) and a Q Exactive HF (Thermo Fisher, USA) mass spectrometer].

\section{Phosphopeptide enrichment}

The workflow for phosphopeptide enrichment and quantitative analysis is shown in Fig. 1. Aliquots of $\mathrm{TiO}_{2}$ (GL Sciences, Japan) beads were washed three times using buffer with $50 \%$ acetonitrile $(\mathrm{ACN})$ containing $2 \%$ trifluoroacetic acid (TFA), saturated with glutamic acid. The $\mathrm{TiO}_{2}$ beads and peptides were dissolved in $800 \mu \mathrm{l}$ of the same buffer and gently shaken at room temperature for $1 \mathrm{~h}$. The $\mathrm{TiO}_{2}$ beads were then washed with $50 \%$ $\mathrm{ACN}$ to remove the non-phosphorylated peptides. The $\mathrm{TiO}_{2}$ beads were washed twice with $50 \% \mathrm{ACN}$ containing $20 \mathrm{mM}$ ammonium acetate. Phosphopeptides were then eluted from the $\mathrm{TiO}_{2}$ beads with $200 \mu \mathrm{l}$ of $0.3 \mathrm{M} \mathrm{NH}_{4} \mathrm{OH}$ one time and with $200 \mu \mathrm{l}$ of $0.5 \mathrm{M} \mathrm{NH}_{4} \mathrm{OH}$ two times. The enriched phosphopeptides were then lyophilized and frozen at $-20^{\circ} \mathrm{C}$ for subsequent use.

\section{High-pH RP-HPLC for peptide separation}

Each sample comprised an equal mixture of digested peptides. The mixture was then separated into ten eluted components by high-pH reversed phase highperformance liquid chromatography (RP-HPLC) (Waters e2695, USA) through a Durashell C18 column $(5-\mu \mathrm{m}$ particle size, 100-Å pore size, $4.6 \mathrm{~mm} \times 250 \mathrm{~mm}$, Agela, China). The liquid phase separation gradient was as follows: $2 \%$ solvent B (100\% ACN containing $5 \mathrm{mM}$ ammonium formate, $\mathrm{pH} 10.0)$ and $98 \%$ solvent $\mathrm{A}(100 \%$ water containing $5 \mathrm{mM}$ ammonium formate, $\mathrm{pH} 10.0$ ) for $10 \mathrm{~min}$, followed by $2-50 \%$ solvent B in $70 \mathrm{~min}$, at a flow rate of $1 \mathrm{ml} / \mathrm{min}$ using a linear gradient. Each elution component was collected every $1 \mathrm{~min}$, and a total of 60 elutions were collected. Every six elutions were mixed together (i.e., 1, 11, 21, 31, 41, 51). Then, the samples were dried and stored at $-80^{\circ} \mathrm{C}$.

\section{Data-dependent acquisition (DDA) spectral library construction}

DDA spectral library construction was performed as previously described [11]. Briefly, groups of ten samples were separated by liquid chromatography, then resuspended in a $0.1 \%$ formic acid water solution containing iRT reagent (Spectronaut, Switzerland) and further analysed by LCMS [consists of a UPLC M-Class system (Waters Corp., Milford, MA, USA) and Q Exactive HF (Thermo Fisher, USA) mass spectrometer]. Each sample was first loaded onto a C18 RP trap column $(5-\mu \mathrm{m}$ particle size, $100-\AA$ pore size, $180-\mu \mathrm{m} \mathrm{ID} \times 20$-mm length; Waters Corp.) and then separated on a C18 RP analytical column $(1.8-\mu \mathrm{m}$ particle size, $100-\mu \mathrm{m} \mathrm{ID} \times 150$-mm length; Waters Corp.] at a flow rate of $300 \mathrm{nl} / \mathrm{min}$ using a linear $\mathrm{ACN}$ gradient of $2-8 \%$ solvent $\mathrm{B}$ in 6 min and then $8-35 \%$ solvent $\mathrm{B}$ in next 114 min (solvent $\mathrm{A}$ : $99.9 \% \mathrm{H}_{2} \mathrm{O}, 0.1 \%$ formic acid; solvent $\mathrm{B}: 99.9 \% \mathrm{ACN}, 0.1 \%$ formic acid). The sample was electrosprayed into the Q Exactive HF $(2.0 \mathrm{kV}$ and $290{ }^{\circ} \mathrm{C}$ ). The Q Exactive HF parameters were set as previously described [11]. The process of DDA for enrichment of phosphopeptides was the same as described above. Proteome Discoverer (version 2.2, Thermo Fisher Scientific) was used to search the DDA mass spectrometry results for the above groups of ten samples to construct DDA spectral libraries. The database was derived from the protein sequences for the Mus musculus downloaded from UniProt (2017/12/07, 16944 sequences), and trypsin, human keratins and Babesia sequences were used to establish a contaminated database. The data search parameters were set as previously described [11].
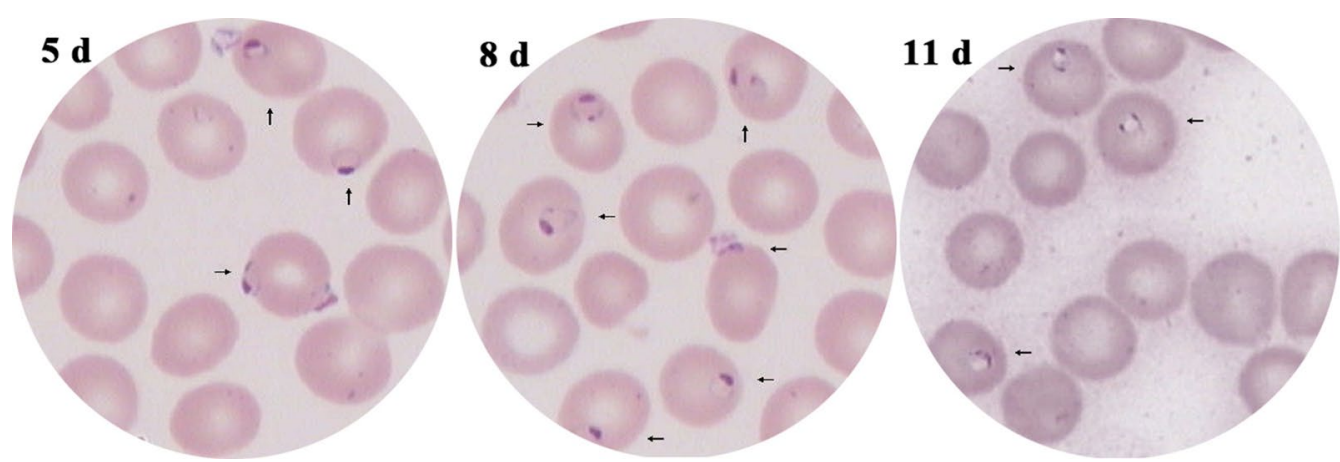

Fig. 1 Observation of red blood cells from mice infected with B. microti. Giemsa blood smear staining of B. microti in red blood cells. B. microti is indicated by arrows 


\section{Data-independent acquisition (DIA) spectral acquisition and data analysis}

DIA analysis was carried out for each sample. The chromatographic conditions for DIA were the same as those for DDA spectral library construction. The DIA mass spectrometry parameters were as follows: (i) DIA mode; scanning range for a full scan, 350-1200 $\mathrm{m} / \mathrm{z}$; resolution of the precursor ion, 60,000; automatic gain control (AGC) target, $3 \times 10^{6}$; maximum ion injection time (maximum IT), $50 \mathrm{~ms}$; (ii) HCD normalized collision energy, 27\%; (iii) DIA MS2 scanning, 34 consecutive windows, each of which was set to $26 \mathrm{~m} / z$ and a $1 \mathrm{~m} / \mathrm{z}$ overlap between two adjacent windows; (iv) MS2 scan resolution, 30,000; AGC target, $1 \times 10^{6}$; maximum IT, set to auto.

DIA findings were analysed using Spectronaut software (version 11.0, Switzerland). The default parameters for DIA data analysis were used, where the false discovery rate (FDR) for proteins and peptides was set to $<1 \%$. The protein expression levels in all treatment groups were compared with the control group, and the ratio was regarded as the change in protein or peptide expression, which was also the basis for further data analysis and discussion. Proteins quantified with at least two unique peptides and whose $Q$ value was $<0.05$ and expression change times $>1.5$ were considered to have significant changes in expression. For phosphopeptides, we only focused on the quantitative phosphopeptide results. If the change in phosphopeptides was $>1.5$ times, the degree of phosphorylation modifications was considered changed.

\section{Bioinformatics analysis}

Bioinformatics analysis was performed for all differentially expressed proteins or phosphopeptides. Proteins with similar expression characteristics were clustered with GProX [12]. The number of clusters was set to 4 , and a fixed regulation threshold (an upper limit of 0.58 for protein upregulation and a lower limit of -0.58 for protein downregulation, corresponding to the original ratios 1.5 and 0.67 , respectively) was used. Principal component analysis (PCA) was performed with online analysis software (http://www.omicsolution.org/wu-kong-beta-linux /main/). PANTHER software (http://pantherdb.org/) was used for Gene Ontology (GO) functional categories. Pathways associated with the differentially expressed proteins were identified using the Kyoto Encyclopedia of Genes and Genomes (KEGG) database (http://www.kegg. jp/kegg/). The tool used for KEGG analysis was KEGG Mapper (https://www.kegg.jp/kegg/tool/map_pathway2. html).
Parallel reaction monitoring (PRM) mass spectrometry and data analysis

To verify the protein expression levels obtained by DIA, ten selected proteins were further quantified by PRM. One signature peptide without missing sites was selected based on DIA data, and each peptide that we selected belonged only to one specific target protein. PRM analysis was performed in the Q-Exactive HF mass spectrometer (Thermo Fisher, USA) with the same LC gradient settings as above. The parameters were set as follows: (i) resolution of the full scan: 60,000; (ii) AGC target: 3e6; (iii) full scan range: $350-1200 \mathrm{~m} / \mathrm{z}$; (iv) maximum IT: $50 \mathrm{~ms}$; (v) MS2 scan resolution: 30,000; (vi) AGC target: 1e5; (vii) maximum IT: $100 \mathrm{~ms}$. The mass spectrometry proteomics data were analysed using Skyline (MacCoss Laboratory, University of Washington) [13]. We assessed and corrected the peak according to the transitions, retention time, mass accuracy and MS/MS spectra. The area under the curve (AUC) of each transition was extracted and exported to Excel for further data analysis.

\section{Results \\ Observation of red blood cells from mice infected with $B$. microti under a microscope}

The results showed that parasitaemia levels in red blood cells after infection reached the highest proportion (nearly 50\%) at 8 days, and the parasitaemia levels substantially decreased at 11 days after infection (nearly 10\%) (Fig. 1). At 19 days after infection, B. microti was not observed in red blood cells.

\section{Effects of $B$. microti infection on the spleen}

The spleens of the mice infected by $B$. microti became enlarged, and some organelles were abnormal. Gross morphological changes in the spleen at different time points after $B$. microti infection are shown in Additional file 1: Figure S1. Changes in the subcellular structure in mice are shown in Fig. 2. As shown in the figure, the endoplasmic reticulum of splenocytes from uninfected mice showed normal morphological characteristics, with the largest number of mitochondria per unit area (14 mitochondria can be observed in the visual field of the same area) and a small number of lysosomes per unit area (4 lysosomes can be observed in the visual field of the same area). At 5 days after infection, the endoplasmic reticulum of spleen cells showed slight dilation and slight degranulation. At this time, the number of mitochondria per unit area decreased significantly (only 4 mitochondria could be observed in the visual field), and the number of lysosomes per unit area was still small (4 lysosomes could be observed in the visual field). Furthermore, the endoplasmic reticulum of spleen cells was obviously dilated and severely degranulated at 8 days after 
infection; at this time, the number of mitochondria per unit area was reduced ( 2 mitochondria could be observed in the visual field), and the number of lysosomes per unit area was still small (2 lysosomes could be observed in the visual field). At this time, autophagosomes appeared. Splenomegaly was most obvious at 11 days after infection (Additional file 1: Figure S1), and the endoplasmic reticulum was still dilated and degranulated. In addition, the number of mitochondria per unit area was still small (3 mitochondria could be observed in the visual field), the number of lysosomes was the greatest (9 lysosomes could be observed in the visual field), and the presence of autophagosomes remained evident during this period. At 19 days after infection, the size of the spleen returned to almost the same as that at 5 days after infection, and the endoplasmic reticulum in spleen cells basically returned to a normal morphology, while the number of mitochondria per unit area was still small (5 mitochondria could be observed in the visual field). At this time, the number of lysosomes decreased (3 lysosomes could be observed in the visual field), and autophagosomes were no longer observed.

\section{Identification and quantification of global proteins and phosphopeptides}

Changes in global protein expression levels and phosphorylation modification in the spleens of mice infected with B. microti were analysed by DIA quantitative proteomics. The whole experimental design is shown in Additional file 1: Figure S1. The numbers of identified proteins in mice in the uninfected group ( 0 day) and after 5 days, 8 days, 11 days and 19 days of $B$. microti infection were 2804, 2890, 2888, 2936 and 2918, respectively; the numbers of proteins that had a coefficient of variation $(\mathrm{CV})$ value $<20 \%$ among four biological repeats in all groups were 2250, 2214, 2270, 2425 and 2241, respectively. PCA was performed on data in four repeats for these five periods (Fig. 3a). The figure shows that the similarity among repeated data in all groups was high, indicating that the reproducibility of the data in four repeats was high, while the five groups of data for the different infection periods were significantly different. The identified results were subject to Venn diagram analysis (Fig. 3b). The number of proteins that were identified in all five periods was 1403, of which 966 proteins were differentially expresses. The information for intersecting proteins is provided in Additional file 2: Dataset S1. The mass spectrometry proteomics data have been deposited in the ProteomeXchange Consortium via the iProX partner repository (accession no. IPX0002204000/PXD019236).

The quantitative results for phosphopeptides in all groups identified by mass spectrometry were analysed using Spectronaut 11 software. The numbers of identified phosphopeptides in mice in the uninfected group (0 day) and after 5 days, 8 days, 11 days and 19 days of B. microti infection were 12,373, 12,689, 12,792, 12,670 and 12,501, respectively; the numbers of phosphopeptides with a $\mathrm{CV}$ value $<20 \%$ among four biological repeats in all groups were 5363, 8638, 9746, 6725 and 8042, respectively. PCA was performed on data from four repeats for these five periods, and the Venn diagram shows 2261 intersecting phosphopeptides in the five periods (Additional file 1: Figure S2). These 2261 phosphopeptides included 2470 phosphorylation modification sites, of which 2065 peptides contained 1 phosphorylation site, 183 peptides contained 2 phosphorylation sites, and 13 peptides contained 3 phosphorylation sites (Fig. 4a). Among 2470 phosphorylation sites, $82.19 \%$ occurred at serine residues, $16.11 \%$ occurred at threonine residues, and $1.70 \%$ occurred at tyrosine residues (Fig. 4b). When the mass spectrometry identification results of the same polypeptide in different periods had a fold change $>1.5$, the

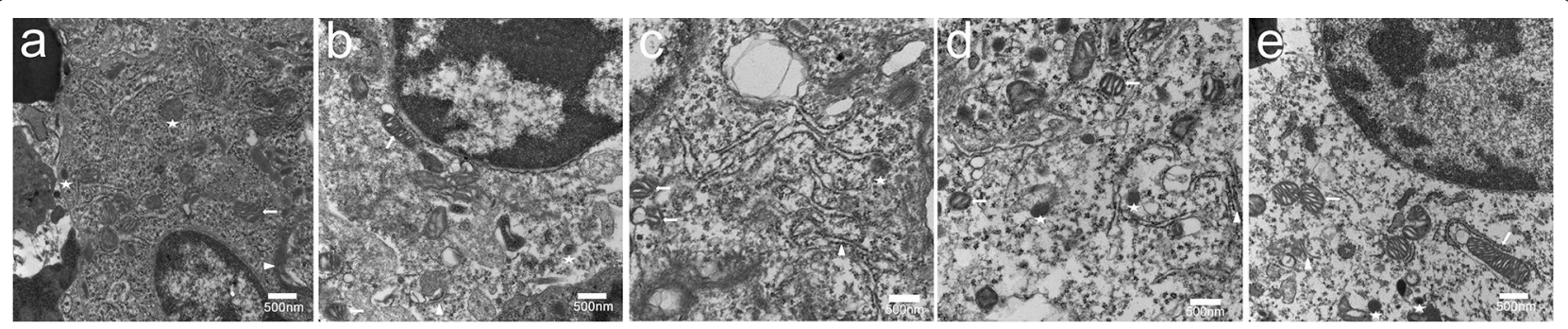

Fig. 2 TEM observation of splenocytes in mice infected with B. microti at different stages. a 0 day (control); b 5 days; c 8 days; d 11 days; e 19 days. The number of mitochondria in mouse splenocytes infected by B. microti was significantly decreased. On the 8th day, the endoplasmic reticulum was obviously dilated, which was accompanied by degranulation. On the 11th day, the numbers of lysosomes increased, and the endoplasmic reticulum was still dilated, which was accompanied by degranulation. By the 19th day after infection, the expansion of the endoplasmic reticulum was significantly reduced, the degranulation was also weakened, and the number of lysosomes returned to the normal level. The short arrow points to mitochondria, the pentagram to the lysosome, the triangle to the endoplasmic reticulum and long scissors to autophagy 
peptide was considered to have differentially changed; in other words, the level of phosphorylation modification at this site changed. A total of 2169 phosphopeptides, corresponding to 1011 proteins, showed differences in mass spectrometry identification results. The information for intersecting phosphopeptides is provided in Additional file 2: Dataset S2. The mass spectrometry proteomics data have been deposited in the ProteomeXchange Consortium via the iProX partner repository (accession no. IPX0002209000/PXD019319).

\section{Cluster analysis and GO annotation analysis of differentially expressed proteins}

All differentially expressed proteins were classified by cluster analysis and GO annotation analysis, which provided information for further analysis of signalling pathways. For the periods of 5 days/ 0 day, 8 days/ 0 day, 11 days $/ 0$ day and 19 days/ 0 day of $B$. microti infection, cluster analysis was performed on 1403 intersecting proteins that had annotation information (Fig. 5). The results showed that Cluster 0 had 437 proteins with differential expression level changes that were not significant. Cluster 1 had 225 proteins, and the expression levels of these proteins were upregulated with increasing parasitaemia levels; however, the expression levels of these proteins slightly decreased with recovery at 19 days. Functions of these proteins were associated with defending against $B$. microti infection. Cluster 2 had 269 proteins. The expression levels of these proteins were downregulated at 5 days, 8 days and 11 days after infection and upregulated at 19 days. Cluster 3 had 244 proteins. The expression levels of these proteins were upregulated at 5 days, 8 days and 11 days after infection and downregulated to normal levels at 19 days. Cluster 4 had 228 proteins. Their expression levels were downregulated at 5 days after infection and gradually upregulated at 8 days, 11 days and 19 days.

Proteins in Cluster 1-Cluster 4 that exhibited expression changes were subject to $\mathrm{GO}$ annotation analysis (Fig. 6). These proteins were classified into the following categories: Biological Process, Cellular Component and Molecular Function (orange, green and blue bars, respectively). Among the four clusters, cellular process and metadata process were the most abundant nodes under the Biological Process node, and binding and catalytic activity were the most abundant nodes under the Molecular Function node. However, cell part and organelle process were the most abundant nodes under the Cellular Component node in Cluster 1, Cluster 2 and Cluster 4. By comparison, membrane and macromolecular complex processes were the most abundant nodes under the Cellular Component node in Cluster 3.

\section{Cluster analysis and GO enrichment analysis of differentially expressed phosphopeptides}

Phosphorylation is one of the most important post-translational modifications that regulate biological functions. All the phosphorylated peptides with different changes were classified to create conditions for further analysis of signalling pathways by cluster analysis and GO annotation analysis.

For the periods of 5 days $/ 0$ day, 8 days $/ 0$ day, 11 days $/ 0$ day and 19 days/0 day of $B$. microti infection, cluster analysis was performed on differentially

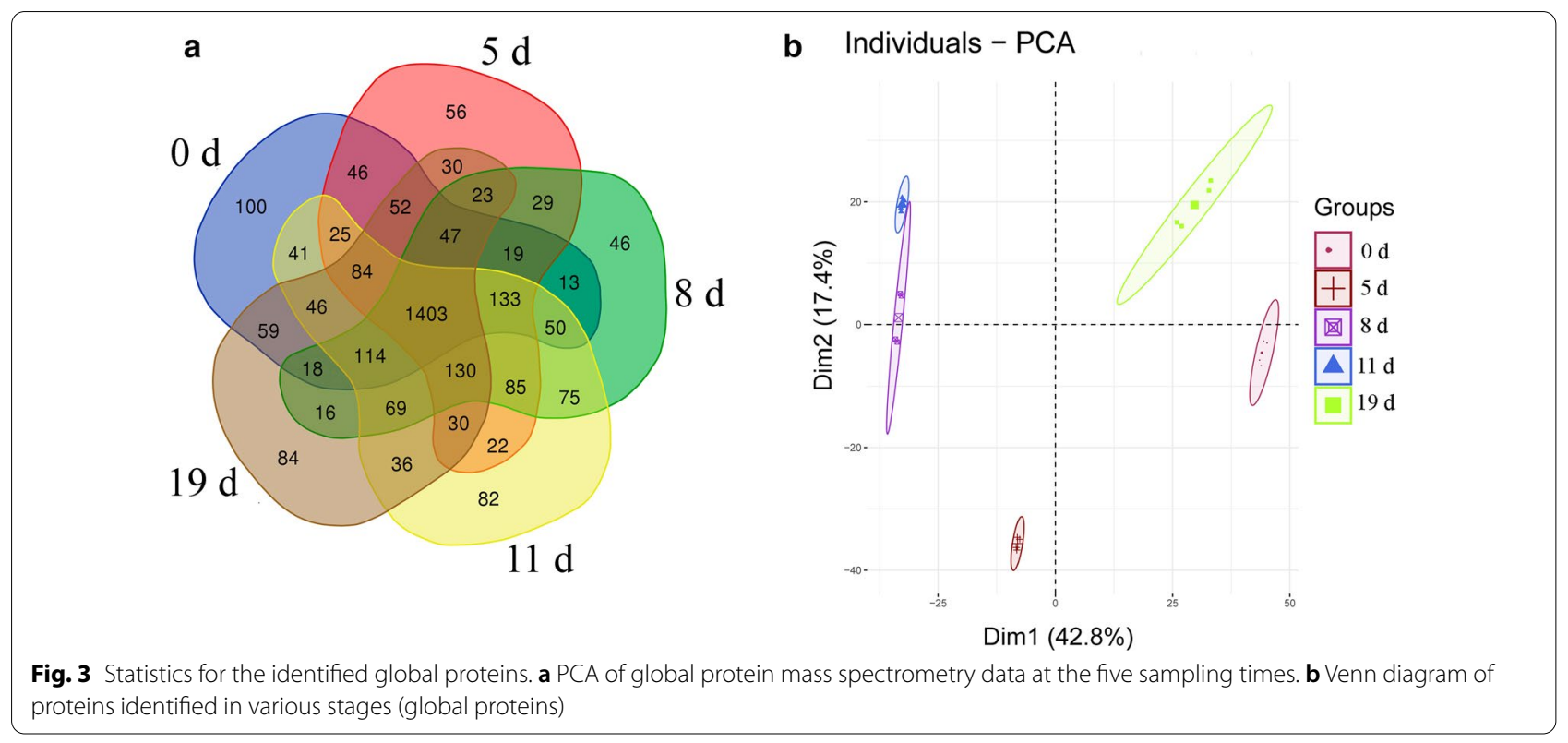



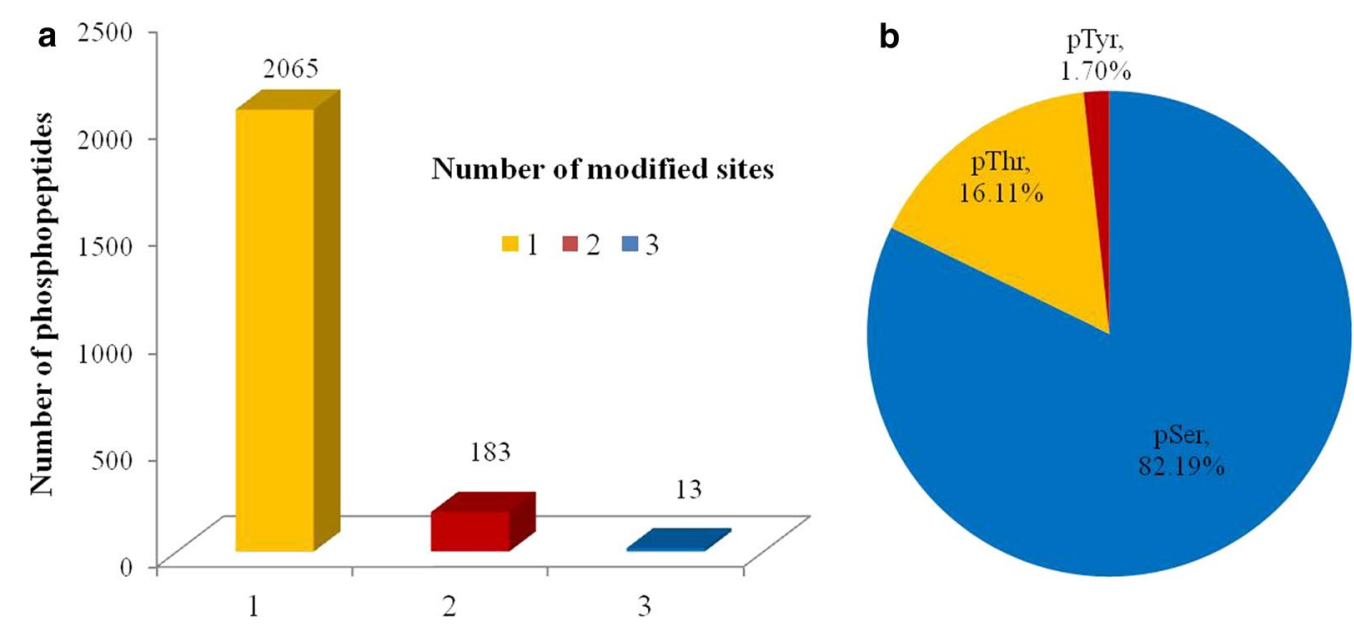

Fig. 4 Statistics for the identified phosphorylated peptides. a Statistical analysis of the number of modification sites on phosphorylated peptide fragments. $\mathbf{b}$ Statistical analysis of percentages of the three types of amino acid phosphorylation

modified phosphopeptides (Additional file 1: Figure S3). These proteins were grouped into five clusters. The results showed that the phosphorylation modification changes in 92 peptides in Cluster 0 were not significant. The phosphorylation modification levels of 560 phosphopeptides in Cluster 1 were upregulated with increasing parasitaemia levels. However, the modification levels were downregulated at 11 days when the parasitaemia levels decreased and then gradually returned to normal levels in the recovery period at 19 days. The modification levels of 547 phosphopeptides in Cluster 2 were downregulated at 5 days, 8 days and 11 days after $B$. microti infection and upregulated at 19 days. The phosphorylation modification levels of 408 phosphopeptides in Cluster 3 were upregulated at 5 days and 8 days and returned to normal levels at 11 days and 19 days. The phosphorylation modification levels of 554 phosphopeptides in Cluster 4 were downregulated at 5 days, 8 days and 11 days and upregulated again at 19 days.

GO annotation was performed on proteins corresponding to differentially expressed phosphopeptides in Cluster 1-Cluster 4 (Additional file 1: Figure S4). These proteins were classified into the following categories: Biological Process, Cellular Component and Molecular Function (orange, green and blue bars, respectively). Among the four clusters, cellular process and metadata process were the most abundant nodes under the Biological Process node, and binding and catalytic activity were the most abundant nodes under the Molecular Function node. In addition, cell part and organelle were the most abundant nodes under the Cellular Component node.
KEGG pathway analysis of differentially expressed proteins and phosphorylated proteins

Regulatory pathways associated with differentially expressed proteins were identified, and their roles in host defence against Babesia infection were determined by analysing KEGG signalling pathways. A total of 966 differentially expressed proteins from Cluster 1-Cluster 4 were analysed for signalling pathway analysis (Fig. 5). A total of 288 signalling pathways were involved (Fig. 7); 153 proteins were involved in metabolic pathways, and 44 proteins were involved in ribosome biogenesis. The following pathways were also involved: the mitogenactivated protein kinase (MAPK) signalling pathway (ko04010), T cell receptor signalling pathway (ko04660) and Amoebiasis pathway (ko05146).

Proteins with different changing trends in the four clusters were also subject to KEGG signalling pathway analysis (Fig. 8). The results of the KEGG signalling pathway analysis for Cluster 2 and Cluster 4 are shown below. Expression levels of proteins in these 2 clusters had stable changing trends. In Cluster 2, 17 proteins were involved in the regulation of the actin cytoskeleton pathway (ko04810), suggesting that Babesia infection in host cells might induce changes in the host cytoskeleton in the early stage. Furthermore, we focused on pathways related to immunity and growth and development. The results showed that nine proteins were involved in the $\mathrm{T}$ cell receptor signalling pathway (ko04660), seven proteins were involved in the MAPK signalling pathway (ko04013), and six proteins were involved in the apoptosis pathway. In Cluster 4, six proteins were involved in the MAPK signalling pathway, and some proteins were involved in the iron metabolism pathway. These pathways 

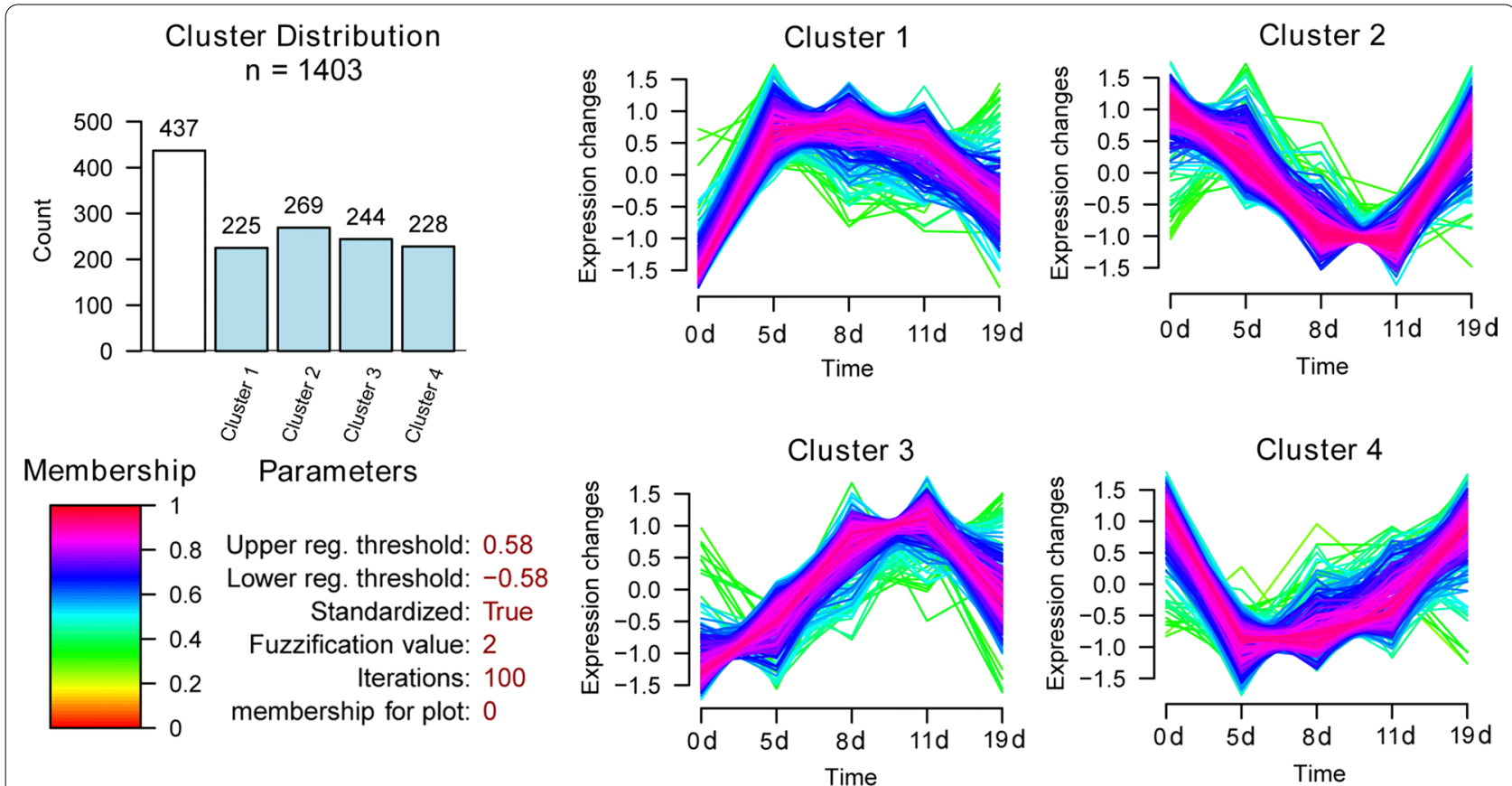

Fig. 5 Cluster analysis of differentially expressed proteins in the spleen tissues of mice infected with B. microti. A log2 value $>0.58$ indicated upregulation, showing that this protein was upregulated, while a $\log 2$ value $<-0.58$ indicated downregulation, showing that this protein was downregulated

play important roles in defending pathogen invasion in the body, regulating iron homeostasis and regulating growth and development in the body.

KEGG signalling pathway analysis was performed on 1011 phosphorylated proteins with phosphorylation modification changes. The results showed that these proteins were involved in a total of 174 signalling pathways (Additional file 1: Figure S5). Immune- and growth and development-related signalling pathways were enriched in different periods, indicating that immune regulation in the body plays important roles in the process of defending against $B$. microti infection. Related pathways involving immunity and growth and development include apoptosis (ko04210), ribosome (ko03010), MAPK signalling (ko04013) and $\mathrm{T}$ cell receptor signalling pathways (ko04660), and 14 proteins were involved in the apoptosis pathway, 13 proteins were involved in the $\mathrm{T}$ cell receptor signalling pathway, and 10 proteins were involved in the MAPK signalling pathway. In addition, proteins with different changing trends in the four clusters were also subject to KEGG signalling pathway analysis (Additional file 1: Figure S6).

\section{PRM to confirm the changes in the key proteins}

The expression changes in ten key proteins at different infection stages were verified by PRM (Additional file 1 :
Figure S7). The quantitative results of the ten proteins were consistent with those shown by the DIA method $[14,15]$.

\section{Discussion}

The spleen is the largest immune organ in mammals [16] and plays substantial roles in the activation and control of immune responses in the body $[17,18]$. The spleen can kill a large number of invading pathogens during blood filtration and is the most important organ in the body for defending against Babesia infection [19, 20]. Although the spleen has a strong immune function, Babesia infection can also cause a series of morphological and physiological changes in the spleen [21]. In this study, we found that the subcellular structure of splenocytes from mice infected with $B$. microt $i$ also changed after in-depth exploration. For example, the endoplasmic reticulum expanded to varying degrees, which was accompanied by degranulation, and many lysosomes and autophagosomes appeared. During this process, the expression and modification of a large number of proteins in splenocytes changed. These proteins mainly participate in infection defence in the body, induction of apoptosis and autophagy, regulation of iron metabolism and cell proliferation and growth-related pathways (Table 1). 


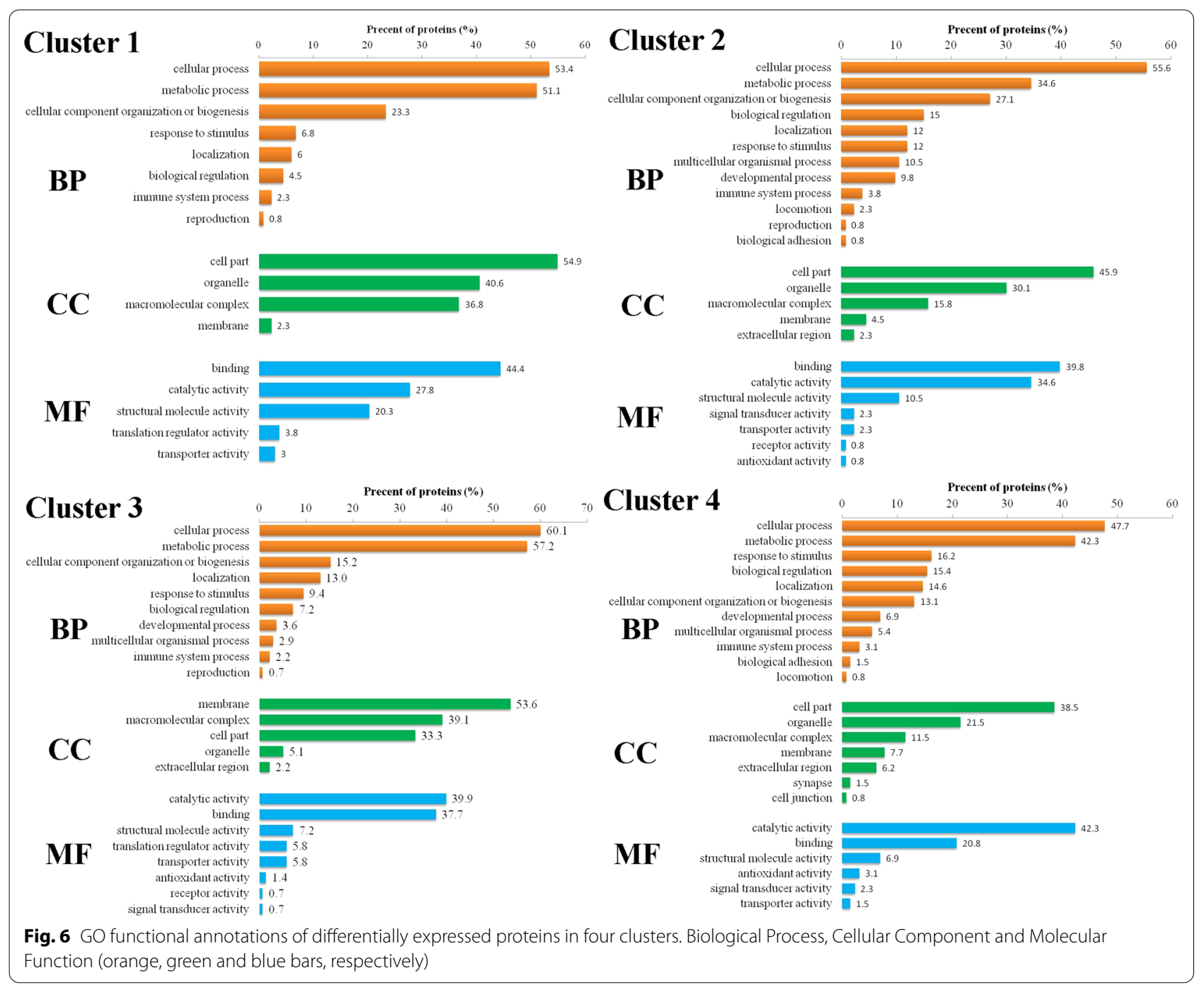

\section{Immune-related proteins}

The quantitative proteomics results in this study showed that the expression of many immune-related proteins changed in the mouse spleen during $B$. microti infection. These proteins mainly participate in physiological activities such as protein degradation in lysosomes, autophagy, apoptosis, inhibition of excessive cell proliferation and viral infection defence to ensure effective killing of $B$. microti.

After hosts are infected with common parasitic protozoans such as Babesia, Plasmodium and Leishmania, lysosomes in host cells can engulf a large number of parasites [22-24]. Cathepsin D (CTSD) belongs to the aspartic protease family. It is localized in lysosomes of various tissues and cells [25] and can participate in various physiological activities in cells including cell apoptosis [26], degrading exogenous pathogens through the autophagylysosome system [27] and promoting protein degradation in lysosomes during antigen presentation [28, 29]. This study showed that the expression level of CTSD was downregulated at 5 days and 8 days after B. microti infection and upregulated after 11 days. After the mice were infected with $B$. microti, the cell structure in spleen was destroyed; in addition, the structure and morphology of organelles such as lysosomes also had abnormalities. We speculate that this might be the cause of the corresponding reduction in the expression level of CTSD in the early stage of infection. With the decrease in the degree of infection, the cell structure in mouse spleen gradually returned to normal. At this time, lysosomes already engulfed a large number of Babesia and a large amount of CTSD was urgently needed for lysosomal degradation of Babesia. Therefore, the expression of level of CTSD was upregulated correspondingly.

Interferon-induced protein 44 (IFI44) is an interferon $\alpha / \beta$-induced protein [30]. Studies have shown that IFI44 


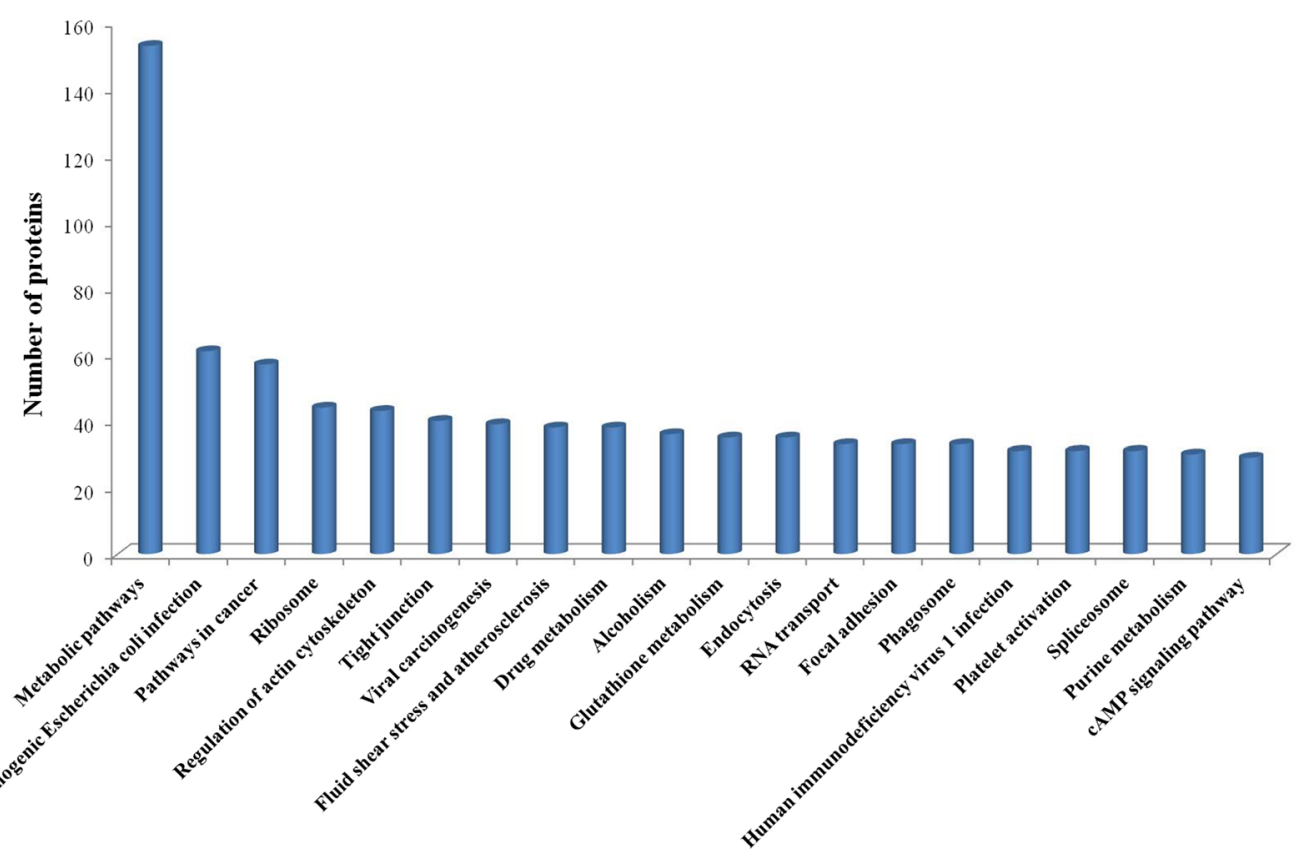

Fig. 7 KEGG pathway analysis of differentially expressed proteins

is a potential inflammatory factor and can defend against viral infection through the inhibition of viral transcription [31]. As an interferon-induced protein, IFI44 expression levels directly reflect IFN $-\alpha / \beta$ activity. IFN $-\alpha / \beta$ plays an important role in defending against infection from many parasites such as Leishmania donovani [32], Plasmodium [33], Toxoplasma [34] and Trypanosome brucei [35]. Therefore, IFI44 is speculated to have broad-spectrum anti-protozoan functions. This study showed that after mice were infected with $B$. microti, the expression level of IFI44 in the spleen was upregulated at 5 days and 8 days and was then gradually downregulated. The expression level returned to a normal level after 19 days. Therefore, we speculate that IFI44 participated in spleen immune responses after $B$. microti infection and directly or indirectly exerted its biological functions to defend against $B$. microti invasion. Although the mechanism of IFI44 involvement in defending against $B$. microti infection currently remains unclear, IFI44 might be able to be used as a marker for screening Babesia infection.

Interleukin-2 enhancer-binding factor 2 (ILF2) and interleukin enhancer-binding factor 3 (ILF3) are components of nuclear factor of activated $\mathrm{T}$ cells (NFAT) [36]. Downregulation of ILF2 expression levels has been shown to inhibit cell proliferation [37], whereas downregulation of IFL3 expression, in addition to inhibition of cell proliferation, also inhibits cell migration and invasion and promotes cell apoptosis [38]. Some parasites such as Babesia, Plasmodium and Leishmania can cause unlimited cell proliferation after infecting hosts to eventually cause diseases in hosts $[39,40]$. This study showed that after B. microti infection in mice, the expression levels of ILF2 and IFL3 in the spleen were downregulated; notably, the expression levels were downregulated to the lowest levels at 11 days. The expression levels returned to normal at 19 days. Therefore, we speculate that $B$. microt $i$ infection in mice might result in excessive cell proliferation; therefore, reduced expression levels of ILF2 and IFL3 were required to inhibit unrestricted cell proliferation and avoid cell lesions.

The quantitative proteomics results for phosphorylated proteins in the spleen showed that phosphorylation modifications of some proteins changed after the spleen was infected by Babesia. These proteins were activated through changes in their phosphorylation modifications. STAT5 is an important transcription factor. After phosphorylation modification, signal transducer and activator of transcription 5A (STAT5A) can initiate target gene transcription to play a critical role in $\mathrm{T}$ cell proliferation and differentiation, thus participating in host immunomodulation [41]. The results of this study showed that the phosphorylation modification level of STAT5 in the spleens of mice after B. microti infection was upregulated at 8 days. We speculate that the main function of STAT5 activation was to promote $\mathrm{T}$ cell proliferation and differentiation [42] to ensure that more $\mathrm{T}$ cells participated in immune responses. With the gradual disappearance of Babesia under the clearance function of host immunity, 


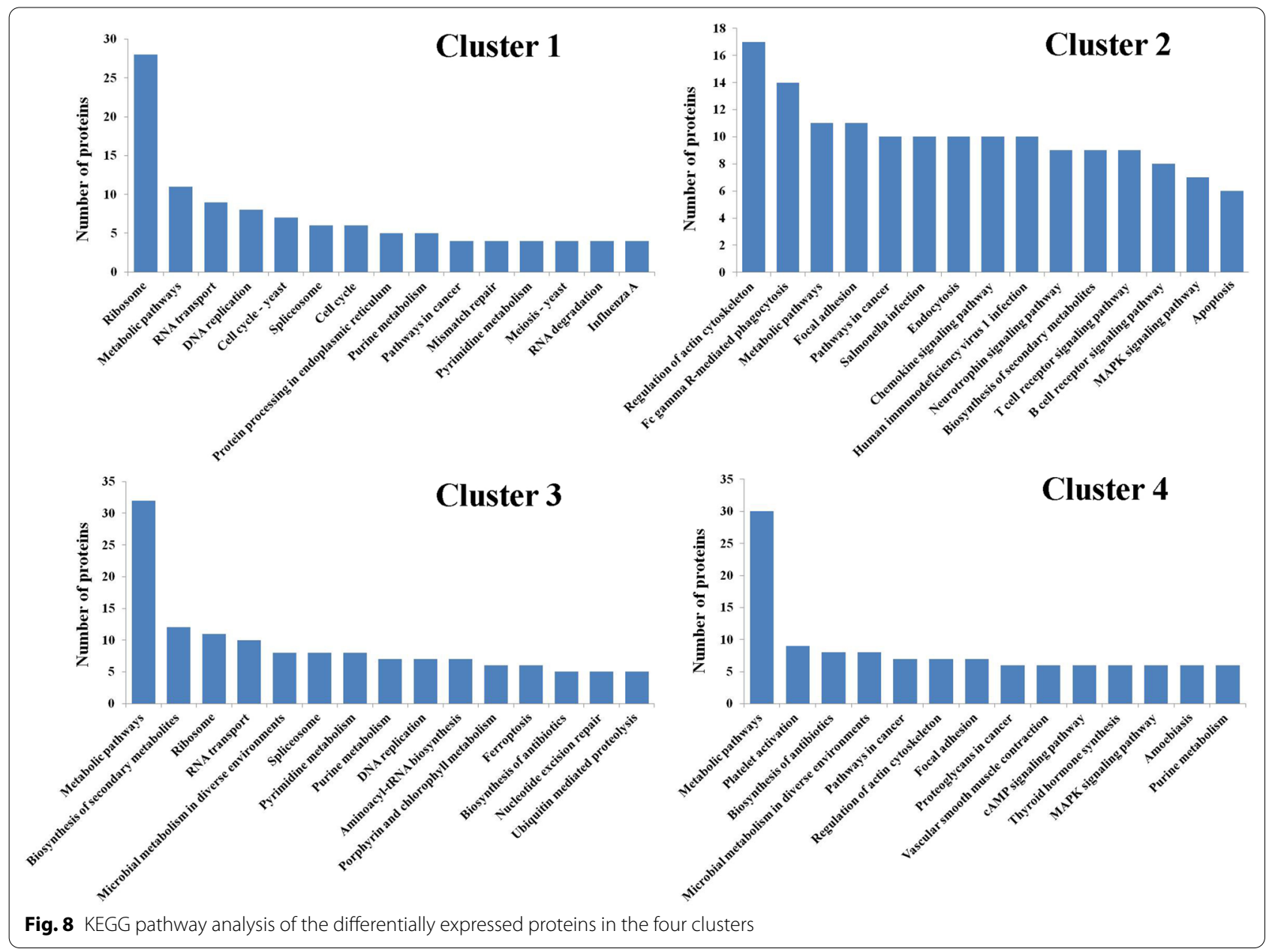

Table 1 Immune-related proteins, iron metabolism-related proteins and growth and development-related proteins in the spleen tissues of mice infected with Babesia microti

\begin{tabular}{|c|c|c|c|c|c|c|}
\hline Protein name & Accession & Description & 5 days & 8 days & 11 days & 19 days \\
\hline CTSD & P18242 & Cathepsin D & $\downarrow$ & $\downarrow$ & $\uparrow$ & $\uparrow$ \\
\hline IFI44 & Q8BV66 & Interferon-induced protein 44 & $\uparrow$ & $\uparrow$ & - & - \\
\hline ILF2 & Q3UXI9 & Interleukin-2 enhancer binding factor 2 & $\downarrow$ & $\downarrow$ & $\downarrow$ & - \\
\hline ILF3 & A0A1L1STE4 & Interleukin enhancer-binding factor 3 & $\downarrow$ & $\downarrow$ & $\downarrow$ & - \\
\hline STAT5A ${ }^{a}$ & P42230 & Signal transducer and activator of transcription $5 \mathrm{~A}$ & - & $\uparrow$ & - & - \\
\hline Lactoferrin & B8YJF9 & Lactoferrin & $\downarrow$ & $\downarrow$ & $\downarrow$ & $\downarrow$ \\
\hline Serotransferrin & Q92111 & Serotransferrin & $\downarrow$ & - & $\uparrow$ & - \\
\hline TfR1 & Q542D9 & Transferrin receptor protein 1 & $\uparrow$ & $\uparrow$ & $\uparrow$ & $\uparrow$ \\
\hline GCLC & P97494 & Glutamate-cysteine ligase & $\uparrow$ & $\uparrow$ & $\uparrow$ & $\uparrow$ \\
\hline GCLM & 009172 & Glutamate-cysteine ligase & - & - & $\uparrow$ & - \\
\hline PKC- $\delta^{a}$ & P28867 & Protein kinase C- $\delta$ & - & $\downarrow$ & $\downarrow$ & - \\
\hline$M A P K 1^{a}$ & P63085 & Mitogen-activated protein kinase 1 & - & - & $\downarrow$ & - \\
\hline MAPK3 $^{\mathrm{a}}$ & D3Z3G6 & Mitogen-activated protein kinase 3 & - & - & $\downarrow$ & - \\
\hline Grb2 & Q60631 & Growth factor receptor-bound protein 2 & $\downarrow$ & $\downarrow$ & $\downarrow$ & - \\
\hline PAK2 & Q8CIN4 & P21-activated kinase 2 & - & $\downarrow$ & $\downarrow$ & - \\
\hline
\end{tabular}

$\uparrow$, Upregulated peptide; $\downarrow$, downregulated peptide; -, no change peptide

a Phosphorylated protein 
the mouse spleen function and structure also gradually returned to normal at 19 days after infection, and the phosphorylation modification level of STAT5 also returned to a normal level. These results indicated that changes in the phosphorylation modification of STAT5 had important immune defence functions during the Babesia infection period, the synthesis of a large amount of proteins was not required, and the normal modification pattern rapidly returned to normal when it was not required in the body. This is a very energy-saving cascade signalling transduction process.

\section{Iron metabolism-related proteins}

The iron ion is one of the important trace elements for the maintenance of life activities in the body [43]. Iron deficiency or excess can both cause adverse effects on health [44-49]. Many parasitic protozoans have the ability to influence iron metabolism in hosts such as Plasmodium and Leishmania. These parasites can take up a large number of iron ions in hosts to maintain their growth and propagation $[50,51]$. When parasites propagate, they utilize hosts to provide enough iron supplements. It has been shown that when the iron content in hosts is too high, protozoan propagation indeed will be promoted [52]. In contrast, when the iron content in hosts is low, the parasitic rate significantly decreases. To maintain an iron element balance in the body, the body finely regulates iron absorption, transport and utilization.

Lactoferrin is an important non-haem iron-binding protein and participates in the regulation of iron homeostasis in the body [53]. In addition, as an immunomodulatory protein, lactoferrin has many functions, including anti-parasitic [54], antibacterial [55], anti-viral [56] and anti-inflammatory [57] actions. Lactoferrin participates in the host defence mechanism through two methods. The first method involves lactoferrin binding to iron in hosts so pathogens cannot acquire enough iron from host cells; therefore, their growth is blocked [58]. The other method involves lactoferrin directly interacting with pathogens to inhibit pathogen adsorption and invasion into target cells [56]. The results in this study showed that after B. microti infection in mice, the expression level of lactoferrin in splenocytes was downregulated during the infection period and upregulated during the recovery period. Therefore, we speculate that the reduction in the expression level of lactoferrin in the spleen in the infection period might be caused by the uptake of a large amount of iron in mice by B. microti to supply their growth needs. At this time, iron deficiency in the body caused excessive expression of iron transport-related proteins, thus decreasing the expression level of lactoferrin. However, with the extension of infection time, the iron content in hosts decreased dramatically. To maintain iron balance in the spleen during the recovery period, the uptake of iron by cells through various methods is needed. At this time, many lactoferrin proteins were required to assist in iron transport; therefore, the expression level of lactoferrin was upregulated.

Serotransferrin is a key protein involved in iron metabolism and in defending against microbial invasion in the body $[59,60]$. It can not only transport iron in the body in a soluble and non-toxic form to participate in iron metabolism [61] but also inhibit the growth of pathogenic microorganisms through the clearance of free iron ions in hosts $[60,62]$. The results of this study showed that the expression level of serotransferrin in the mouse spleen after $B$. microti infection was downregulated at 5 days and upregulated at 11 days. This regulation pattern for serotransferrin was similar to that for lactoferrin because they had similar functions in iron metabolism and anti-pathogen activities. They both have iron transport functions [63, 64]. In addition, lactoferrin also has iron ion-binding functions [54]. The coordinating regulation of these two proteins not only inhibited pathogen invasion in the body but also regulated iron balance in the body.

Transferrin receptor protein 1 (TfR1) distributes on the surfaces of mammalian cells to mediate the entry of iron taken up by transferrin from outside cells into cells [65]. The expression level of TfR 1 has been shown to be negatively correlated with the iron reserve in the body [66]. When iron is deficient in the body, cells increase iron intake through the expression of high levels of TfR 1 [47]. In contrast, when iron is excessive, the expression level of TfR1 will decrease correspondingly to decrease iron intake [67]. This study showed that after mice were infected with $B$. microti, the expression level of TfR1 was significantly upregulated in the mouse spleen, and the fold upregulation peaked at 11 days. With the gradual recovery of the body at 19 days, the expression level of TfR1 also recovered to a normal level. Therefore, we speculate that the characteristics of expression changes in TfR1 mainly reflect a dramatic reduction in iron reserves due to the consumption of a large amount of iron ions in mouse splenocytes by $B$. microti after mice were infected with $B$. microti. To maintain iron ion homeostasis, cells had to express high levels of TfR1 to accelerate intracellular iron ion intake.

Glutamate-cysteine ligase (GCL) is a rate-limiting enzyme of glutathione (GSH) synthesis [68]. It is a heterodimer composed of a modifier subunit (GCLM) and a catalytic subunit (GCLC) [69]. The results of this study showed that the expression of GCLM in the mouse spleen at 5 days after $B$. microti infection was continuously upregulated and returned to a normal level at 19 days, whereas GCLC expression was upregulated at 
11 days and returned to a normal level at 19 days. These results indicated that the GCL expression level increased correspondingly after splenocytes were infected with $B$. microti. With the decrease in the infection level of B. microti, the GCL expression level also returned to a normal level. Infection of hosts by some common parasitic protozoans can promote an increase in oxygen free radical levels in the body and thus induce oxidative stress responses in the body [70]. GSH protects cells from oxidative damage [71], and the first step of GSH synthesis is catalysis by GCL [72]. Therefore, we speculate that the GCL expression level increased in the spleen after mice were infected with $B$. microti to effectively accelerate GSH biosynthesis. The presence of a large amount of GSH ensured high oxygen free radical clearance and antioxidant abilities [73] to maintain homeostasis in splenocytes.

\section{Growth and development-related proteins}

This study showed that the expression levels or phosphorylation modification levels of many proteins involved in growth and development changed in mouse spleen during $B$. microti infection. Certain protozoan infections cause uncontrolled proliferation of host cells [74]. When the condition is severe, infection may even result in host organ failure until death [75]. To prevent excessive cell proliferation, the host body will adopt an effective response mechanism. Protein kinase $C-\delta(\mathrm{PKC}-\delta)$ is a Ser/Thr-specific kinase involved in many basic cellular processes, including growth and differentiation [76]. Under the function of many cytokines, including IFN- $\alpha$, PKC- $\delta$ has been shown to be activated by phosphorylation. Activated PKC- $\delta$ can inhibit cell proliferation and promote cell apoptosis $[77,78]$. This study showed that at 8 days and 11 days after $B$. microt $i$ infection in mice, both PKC- $\delta$ expression in the spleen and the phosphorylation modification level were downregulated. We speculate that this pattern of change in PKC- $\delta$ during the infection period prevented excessive proliferation of splenocytes during the Babesia infection period to avoid body damage.

MAPK is a protein kinase composed of Ser/Thr kinases [79]. The MAPK signal transduction pathway is linked with cell surface growth factors through growth factor receptor-bound protein 2 (Grb2) [80]. MAPK1 regulates cell proliferation, survival, adhesion and migration through the phosphorylation of hundreds of nuclear substrates and cytoplasmic substrates in cells [81]. MAPK3 also plays a critical role in cell proliferation [82]. We found that the phosphorylation modification level of MAPK1 was significantly downregulated at 11 days. The phosphorylation modification level of
MAPK3 was significantly downregulated, and the fold downregulation was the highest at 11 days. Insufficient MAPK3/1 expression has been shown to block cell proliferation [82, 83]. Dephosphorylation of MAPK3/1 inhibits cell proliferation and differentiation [84]. In addition, this study showed that the expression level of Grb2 was downregulated after B. microti infection in mice and returned to a normal level at 19 days. The reduction in the Grb2 expression level reduced the abilities of various cytokines in response to the induction of proliferation signal transduction [85]. Therefore, we speculate that the regulation patterns of these MAPK signal transduction-related proteins in mouse spleen effectively inhibited the unrestricted proliferation of host cells during the infection period.

Babesia infection in host cells results in insufficient blood glucose in hosts [86]. P21-activated kinase 2 (PAK2) is an important participant in the insulin signalling pathway and glucose homeostasis [87]. Downregulation of PAK2 expression has been shown to promote glucose uptake [88]. This study showed that after $B$. microti infection in mice, the expression level of PAK2 in the spleen was downregulated at 8 days and 11 days and was close to a normal level at 19 days. We speculate that the blood glucose level decreased after B. microti infection in mice. Cells reduced the PAK2 expression level to promote glucose uptake to maintain glucose homeostasis.

\section{Conclusions}

In this study, the roles of different proteins in the spleen in response to $B$. microti infection were analysed by high-throughput quantitative proteomics. Studies have shown that as the largest immune organ, the spleen responds to infections through specific immune-related proteins. At the same time, the spleen reduces the iron content in the body by regulating the expression levels of iron metabolism-related proteins, thereby reducing the degree of $B$. microti infection. The expression of some growth and development-related proteins was also reduced to inhibit excessive proliferation of cells, thereby preventing excessive damage to the spleen. By analysing the characteristics of these proteins, we can further understand the molecular regulatory mechanism of the spleen in response to infection, thus creating conditions for improving the diagnostic efficiency and treatment of babesiosis.

\section{Supplementary Information}

The online version contains supplementary material available at https://doi. org/10.1186/s13071-020-04574-5. 
Additional file 1: Figure S1. The whole experimental design for the proteomics analysis of global proteins and phosphorylated proteins in spleen tissues from mice infected with B. microti. The photos of the spleen show the spleen morphology in different stages. Figure S2. Statistics for the identified phosphorylated peptides. (a) Venn diagram of phosphorylated peptide fragments identified at all stages. (b) PCA of phosphorylated peptide mass spectrometry data at the 5 sampling times. Figure S3. Cluster analysis of differentially phosphorylated peptides in the spleen tissues of mice infected with B. microti. A log2 value $>0.58$ indicated upregulation, showing that this peptide and its phosphorylation modification level were upregulated. A log 2 value $<-0.58$ indicated downregulation, showing that this peptide and its phosphorylation modification level were downregulated. Figure S4. GO functional annotations of differentially phosphorylated proteins. Biological Process, Cellular Component and Molecular Function (orange, green and blue bars, respectively). Figure S5. KEGG pathway analysis of the differentially phosphorylated proteins. Figure S6. KEGG pathway analysis of the differentially phosphorylated proteins in the four clusters. Figure S7. PRM analysis of the ten key proteins. The expression trends of ten key proteins and their corresponding peptides are basically the same.

Additional file 2: Dataset S1. Information for intersecting global proteins. Dataset S2. Information for intersecting phosphopeptides.

\section{Abbreviations}

DIA: Data-independent acquisition; CTSD: Cathepsin D; IFI44: Interferoninduced protein 44; ILF2: Interleukin-2 enhancer-binding factor 2; ILF3: Interleukin enhancer-binding factor 3; STAT5A: Signal transducer and activator of transcription 5A; TfR1: Transferrin receptor protein 1; GCL: Glutamate-cysteine ligase; PKC- $\delta$ : Protein kinase C- $\delta$; MAPK: Mitogen-activated protein kinase; Grb2: Growth factor receptor-bound protein 2; PAK2: P21-activated kinase 2; TEM: Transmission electron microscope; ACN: Acetonitrile; TFA: Trifluoroacetic acid; RP-HPLC: Reversed phase high-performance liquid chromatography; DDA: Data-dependent acquisition; AGC: Automatic gain control; FDR: False discovery rate; PCA: Principal component analysis; GO: Gene Ontology; KEGG: Kyoto Encyclopedia of Genes and Genomes; PRM: Parallel reaction monitoring AUC: Area under the curve; CV: Coefficient of variation; NFAT: Nuclear factor of activated T cells; GSH: Glutathione; GCLM: Glutamate-cysteine ligase modifier subunit; GCLC: Glutamate-cysteine ligase catalytic subunit.

\section{Acknowledgements}

The authors thank the Institute of Laboratory Animal Sciences, Chinese Academy of Medical Sciences, for donating B. microti in this experiment.

\section{Authors' contributions}

$H W$ designed the experiments. XX wrote the initial manuscript. SR, XY, AM, YH and $X W$ analysed the data and performed the experiments. MW, HL and XZ prepared the figures. $J L$ designed the experiments and corrected the manuscript. All authors read and approved the final manuscript.

\section{Funding}

This work was supported by the Natural Science Fund for Distinguished Young Scholars of Hebei Normal University (No. L2017J04).

\section{Availability of data and materials}

Data supporting the conclusions of this article are included within the article. The mass spectrometry proteomics data have been deposited in the ProteomeXchange Consortium via the iProX partner repository (accession no. IPX0002204000/PXD019236; no. IPX0002209000/PXD019319).

\section{Ethics approval and consent to participate}

Not applicable.

\section{Consent for publication}

Not applicable.

\section{Competing interests}

The authors declare no competing or financial interests.

\section{Author details}

${ }^{1}$ Hebei Key Laboratory of Animal Physiology, Biochemistry and Molecular Biology, College of Life Sciences, Hebei Normal University, Shijiazhuang 050024, Hebei, People's Republic of China. ${ }^{2}$ The Fourth Hospital of Hebei Medical University, Shijiazhuang 050011, Hebei, People's Republic of China. ${ }^{3}$ Department of Pathogenic Biology, College of Basic Medicine, Hebei Medical University, Shijiazhuang 050017, Hebei, People's Republic of China. ${ }^{4}$ Instrumental Analysis Center, Hebei Normal University, Shijiazhuang 050024, Hebei, People's Republic of China.

Received: 21 September 2020 Accepted: 29 December 2020

Published online: 19 January 2021

\section{References}

1. Schnittger $L$, Rodriguez AE, Florin-Christensen M, Morrison DA. Babesia: a world emerging. Infect Genet Evol. 2012;12:1788-809.

2. Lobo CA, Cursino-Santos JR, Alhassan A, Rodrigues M. Babesia: an emerging infectious threat in transfusion medicine. PLoS Pathog. 2013;9:e1003387.

3. Krause PJ. Human babesiosis. Int J Parasitol. 2019:49:165-74.

4. Liu AH, Yin H, Guan GQ, Schnittger L, Liu ZJ, Ma ML, et al. At least two genetically distinct large Babesia species infective to sheep and goats in China. Vet Parasitol. 2007;147:246-51.

5. Fang DC, McCullough J. Transfusion-transmitted Babesia microti. Transfus Med Rev. 2016;30:132-8.

6. Telford SR, Spielman A. Reservoir competence of white-footed mice for Babesia microti. J Med Entomol. 1993:30:223-7.

7. Bloch EM, Kumar S, Krause PJ. Persistence of Babesia microti infection in humans. Pathogens. 2019;8:102.

8. Golub R, Tan J, Watanabe T, Brendolan A. Origin and immunological functions of spleen stromal cells. Trends Immunol. 2018:39:503-14.

9. Ludwig C, Gillet L, Rosenberger G, Amon S, Collins BC, Aebersold R. Dataindependent acquisition-based SWATH-MS for quantitative proteomics: a tutorial. Mol Syst Biol. 2018;14:e8126.

10. Xu B, Liu XF, Cai YC, Huang JL, Zhang RX, Chen JH, et al. Screening for biomarkers reflecting the progression of Babesia microti infection. Parasite Vectors. 2018:11:379.

11. Hawkins LJ, Wang MJ, Zhang BW, Xiao Q, Wang H, Storey KB. Glucose and urea metabolic enzymes are differentially phosphorylated during freezing, anoxia, and dehydration exposures in a freeze tolerant frog. Comp Biochem Physiol Part D Genomics Proteomics. 2019;30:1-13.

12. Rigbolt KTG, Vanselow JT, Blagoev B. GProX, a user-friendly platform for bioinformatics analysis and visualization of quantitative proteomics data. Mol Cell Proteomics. 2011;10:0110.007450.

13. MacLean B, Tomazela DM, Shulman N, Chambers M, Finney GL, Frewen B, et al. Skyline: an open source document editor for creating and analyzing targeted proteomics experiments. Bioinformatics. 2010;26:966-8.

14. Peterson AC, Russell JD, Bailey DJ, Westphall MS, Coon JJ. Parallel reaction monitoring for high resolution and high mass accuracy quantitative, targeted proteomics. Mol Cell Proteomics. 2012;11:1475-88.

15. Guan SH, Moran MF, Ma B. Prediction of LC-MS/MS properties of peptides from sequence by deep learning. Mol Cell Proteomics. 2019;18:2099-107.

16. Li L, Duan MB, Chen WS, Jiang A, Li XM, Yang J, et al. The spleen in liver cirrhosis: revisiting an old enemy with novel targets. J Transl Med. 2017;15:111.

17. Lewis SM, Williams A, Eisenbarth SC. Structure-function of the immune system in the spleen. Sci Immunol. 2019;4:eaau6085.

18. Bronte $\mathrm{V}$, Pittet MJ. The spleen in local and systemic regulation of immunity. Immunity. 2013;39:806-18.

19. Coleman JL, LeVine D, Thill C, Kuhlow C, Benach JL. Babesia microti and Borrelia burgdorferi follow independent courses of infection in mice. J Infect Dis. 2005;192:1634-41.

20. Genda J, Negron EA, Lotfipour M, Balabhadra S, Desai DS, Craft DW, et al. Severe Babesia microti infection in an immunocompetent host in Pennsylvania. J Investig Med High Impact Case Rep. 2016:4:2324709616663774.

21. Djokic V, Akoolo L, Parveen N. Babesia microti infection changes host spleen architecture and is cleared by a Th1 immune response. Front Microbiol. 2018;9:85 
22. Agbede RI, Kemp DH, Hoyte HM. Babesia bovis infection of secretory cells in the gut of the vector tick Boophilus microplus. Int Parasitol. 1986:16:109-14.

23. Vijayan K, Cestari I, Mast FD, Glennon EKK, McDermott SM, Kain HS, et al. Plasmodium secretion induces hepatocyte lysosome exocytosis and promotes parasite entry. iScience. 2019;21:603-11.

24. Smirlis D, Dingli F, Pescher P, Prina E, Loew D, Rachidi N, et al. SILACbased quantitative proteomics reveals pleiotropic, phenotypic modulation in primary murine macrophages infected with the protozoan pathogen Leishmania donovani. J Proteomics. 2020;213:103617.

25. Yu CP, Cha Y, Wu F, Xu XB, Qin L, Du M. Molecular cloning and functional characterization of cathepsin D from sea cucumber Apostichopus japonicus. Fish Shellfish Immunol. 2017;70:553-9.

26. Mehanna S, Suzuki C, Shibata M, Sunabori T, Imanaka T, Araki K, et al. Cathepsin D in pancreatic acinar cells is implicated in cathepsin B and $L$ degradation, but not in autophagic activity. Biochem Biophys Res Commun. 2016;469:405-11.

27. Suzuki C, Tanida I, Ohmuraya M, Oliva Trejo JA, Kakuta S. Lack of cathepsin D in the renal proximal tubular cells resulted in increased sensitivity against renal ischemia/reperfusion injury. Int J Mol. 2019;20:1711.

28. Benes P, Vetvicka V, Fusek M. Cathepsin D-many functions of one aspartic protease. Crit Rev Oncol Hematol. 2008;68:12-28.

29. Hausmann M, Obermeier F, Schreiter K, Spottl T, Falk W, Schölmerich $J$, et al. Cathepsin D is up-regulated in inflammatory bowel disease macrophages. Clin Exp Immunol. 2004;136:157-67.

30. Power D, Santoso N, Dieringer M, Yu J, Huang HC, Simpson S, et al. IFl44 suppresses HIV-1 LTR promoter activity and facilitates its latency. Virology. 2015;481:142-50.

31. DeDiego ML, Nogales A, Martinez-Sobrido L, Topham DJ. Interferoninduced protein 44 interacts with cellular FK506-binding protein 5 , negatively regulates host antiviral responses, and supports virus replication. mBio. 2019;10:e01839-19.

32. Kumar R, Bunn PT, Sankar Singh S, Ng SS, de Oca MM, Labastida Rivera FD, et al. Type I interferons suppress anti-parasitic immunity and can be targeted to improve treatment of visceral leishmaniasis. Cell Rep. 2020;30:2512-2525.e9.

33. Yu X, Cai BW, Wang MJ, Tan P, Ding XL, Wu J, et al. Cross-regulation of two type I interferon signaling pathways in plasmacytoid dendritic cells controls anti-malaria immunity and host mortality. Immunity. 2016:45:1093-107.

34. Orellana MA, Suzuki Y, Araujo F, Remington JS. Role of beta interferon in resistance to Toxoplasma gondii infection. Infect Immun. 1991;59:3287-90

35. Lopez R, Demick KP, Mansfield JM, Paulnock DM. Type I IFNs play a role in early resistance, but subsequent susceptibility, to the African Trypanosomes. J Immunol. 2008;181:4908-17.

36. Lin HF, Shao JZ, Xiang LX, Wang HJ. Molecular cloning, characterization and expression analysis of grass carp (Ctenopharyngodon idellus) NF45 (ILF2) CDNA, a subunit of the nuclear factor of activated T-cells (NF-AT). Fish Shellfish Immunol. 2006;21:385-92.

37. Ni TT, Mao GX, Xue Q, Liu YF, Chen BY, Cui XF, et al. Upregulated expression of ILF2 in non-small cell lung cancer is associated with tumor cell proliferation and poor prognosis. J Mol Histol. 2015;46:325-35.

38. Hu XH, Dai J, Shang HL, Zhao ZX, Hao YD. SP1-mediated upregulation of IncRNA ILF3-AS1 functions a ceRNA for miR-212 to contribute to osteosarcoma progression via modulation of SOX5. Biochem Biophys Res Commun. 2019;511:510-7.

39. Lashnits E, Neupane P, Bradley JM, Richardson T, Thomas R, Linder KE, et al. Molecular prevalence of Bartonella, Babesia, and Hemotropic Mycoplasma species in dogs with hemangiosarcoma from across the United States. PLoS ONE. 2020;15:e0227234.

40. Schwing A, Pomares C, Majoor A, Boyer L, Marty P, Michel G. Leishmania infection: misdiagnosis as cancer and tumor-promoting potential. Acta Trop. 2018;197:104855.

41. Orlova A, Wagner C, de Araujo ED, Bajusz D, Neubauer HA, Herling M, et al. Direct targeting options for STAT3 and STAT5 in cancer. Cancers. 2019;11:1930.

42. Wei L, Laurence A, O'Shea JJ. New insights into the roles of Stat5a/b and Stat3 in T cell development and differentiation. Semin Cell Dev Biol. 2008;19:394-400.
43. Abdizadeh H, Rana Atilgan A, Atilgan C. Mechanisms by which salt concentration moderates the dynamics of human serum transferrin. J Phys Chem $B$. 2017:121:4778-89.

44. Powell LW, Seckington RC, Deugnier Y. Haemochromatosis. Lancet. 2016:388:706-16

45. Muckenthaler MU, Rivella S, Hentze MW, Galy B. A red carpet for iron metabolism. Cell. 2017;168:344-61.

46. Brissot P, Bernard DG, Brissot E, Loréal O, Troadec MB. Rare anemias due to genetic iron metabolism defects. Mutat Res. 2018;777:52-63.

47. Miyazawa M, Bogdan AR, Tsuji Y. Perturbation of iron metabolism by cisplatin through inhibition of iron regulatory protein 2. Cell Chem Biol. 2019;26:85-97.

48. Gozzelino R, Arosio P. The importance of iron in pathophysiologic conditions. Front Pharmacol. 2015;6:26

49. Zhang C, Zhang F. Iron homeostasis and tumorigenesis: molecular mechanisms and therapeutic opportunities. Protein Cell. 2015;6:88-100.

50. Zhao H, Konishi A, Fujita Y, Yagi M, Ohata K, Aoshi T, et al. Lipocalin 2 bolsters innate and adaptive immune responses to blood-stage malaria infection by reinforcing host iron metabolism. Cell Host Microbe. 2012;12:705-16.

51. Malafaia G, de Nadai Marcon L, de Fátima Pereira L, Maria Lúcia P, Aparecida Rezende S. Leishmania chagasi: effect of the iron deficiency on the infection in BALB/c mice. Exp Parasitol. 2011;127:719-23.

52. Azcárate IG, Sánchez-Jaut S, Marín-García P, Linares M, Pérez-Benavente S, García-Sánchez M, et al. Iron supplementation in mouse expands cellular innate defences in spleen and defers lethal malaria infection. Biochim Biophys Acta Mol Basis Dis. 2017;1863:3049-59.

53. Mayeur S, Spahis S, Pouliot Y, Levy E. Lactoferrin, a pleiotropic protein in health and disease. Antioxid Redox Signal. 2016;24:813-36.

54. Karav S, German JB, Rouquié C, Le Parc A, Barile D. Studying lactoferrin N-glycosylation. Int J Mol Sci. 2017;18:870

55. Buziashvili A, Cherednichenko L, Kropyvko S, Yemets A. Transgenic tomato lines expressing human lactoferrin show increased resistance to bacterial and fungal pathogens. Biocatal Agric Biotechnol. 2020;25:101602.

56. Ganz T. Iron and infection. Int J Hematol. 2018;107:7-15.

57. Conneely OM. Antiinflammatory activities of lactoferrin. J Am Coll Nutr. 2001;20(389-95):396-7.

58. Sherman MP, Bennett SH, Hwang FFY, Yu C. Neonatal small bowel epithelia: enhancing anti-bacterial defense with lactoferrin and lactobacillus GG. Biometals. 2004;17:285-9.

59. Golizeh M, Lee K, Ilchenko S, Ösme A, Bena J, Sadygov RG, et al. Increased serotransferrin and ceruloplasmin turnover in dietcontrolled patients with type 2 diabetes. Free Radic Biol Med. 2017;113:461-9.

60. Lin L, Pantapalangkoor P, Tan B, Bruhn KW, Ho T, Nielsen T, et al. Transferrin iron starvation therapy for lethal bacterial and fungal infections. J Infect Dis. 2014:210:254-64

61. Elsayed ME, Sharif MU, Stack AG. Transferrin saturation: a body iron biomarker. Adv Clin Chem. 2016:75:71-97.

62. Bruhn KW, Spellberg B. Transferrin-mediated iron sequestration as a novel therapy for bacterial and fungal infections. Curr Opin Microbiol. 2015;27:57-61.

63. Darmawan KK, Karagiannis TC, Hughes JG, Small DM, Hung A. High temperature induced structural changes of apo-lactoferrin and interactions with $\beta$-lactoglobulin and a-lactalbumin for potential encapsulation strategies. Food Hydrocoll. 2020;105:105817.

64. Choudhury D, Thakurta PG, Dasgupta R, Sen U, Biswas S, Chakrabarti C, et al. Purification and preliminary X-ray studies on hen serotransferrin in apo- and holo-forms. Biochem Biophys Res Commun. 2002;295:125-8.

65. Al-Refaei MA, Makki MR, Ali MH. Structure prediction of transferrin receptor protein 1 (TfR1) by homology modelling, docking, and molecular dynamics simulation studies. Heliyon. 2016;6:e03221.

66. Barisani D, Conte D. Transferrin receptor 1 (TfR1) and putative stimulator of Fe transport (SFT) expression in iron deficiency and overload: an overview. Blood Cells Mol Dis. 2002;29:498-505.

67. Wang B, Zhang JQ, Song F, Tian M, Shi BZ, Jiang H, et al. EGFR regulates iron homeostasis to promote cancer growth through redistribution of transferrin receptor 1. Cancer Lett. 2016:381:331-40.

68. Pereda J, Escobar J, Sandoval J, Rodríguez JL, Sabater L, Pallardó FV, et al. Glutamate cysteine ligase up-regulation fails in necrotizing pancreatitis. Free Radic Biol Med. 2008:44:1599-609. 
69. Wiśniewski M, Lapiński M, Zdziarska A, Długosz E, Bąska P. Molecular cloning and analysis of Ancylostoma ceylanicum glutamate-cysteine ligase. Mol Biochem Parasitol. 2014;196:12-20.

70. Singh K, Ali V, Pratap Singh K, Gupta P, Suman SS, Ghosh AK, et al. Deciphering the interplay between cysteine synthase and thiol cascade proteins in modulating Amphotericin B resistance and survival of Leishmania donovani under oxidative stress. Redox Biol. 2017:12:350-66.

71. Yoshioka Y, Kadoi H, Yamamuro A, Ishimaru Y, Maeda S. Noradrenaline increases intracellular glutathione in human astrocytoma U-251 MG cells by inducing lutamate-cysteine ligase protein via $\beta 3$-adrenoceptor stimulation. Eur J Pharmacol. 2016;5:51-61.

72. Raffa M, Hadj Jrad BB, Haj Khelil A, Kerkeni A, Mechri A. Association of polymorphism in glutamate-cysteine ligase catalytic subunit gene with schizophrenia: a case-control study in a Tunisian population. Gene Rep. 2016:4:249-52.

73. Tualeka AR, Martiana T, Ahsan A, Russeng SS, Meidikayanti W. Association between malondialdehyde and glutathione (L-gamma-Glutamyl-CysteinylGlycine/GSH) levels on workers exposed to benzene in Indonesia. Open Access Maced J Med Sci. 2019;7:1198-202.

74. Dobbelaere DAE, Rottenberg S. Theileria-induced leukocyte transformation. Curr Opin Microbiol. 2003;6:377-82.

75. Joseph JT, Roy SS, Shams N, Visintainer P, Nadelman RB, Hosur S, et al. Babesiosis in lower hudson valley, New York, USA. Emerg Infect Dis. 2011;17:843-7.

76. Slepchenko KG, Holub JM, Li YV. Intracellular zinc increase affects phosphorylation state and subcellular localization of protein kinase C delta ( $\delta$ ). Cell Signal. 2018;44:148-57.

77. Zhang DM, Fu MJ, Li LY, Ye H, Song ZQ, Piao TJ. PKC- $\delta$ attenuates the cancer stem cell among squamous cell carcinoma cells through down-regulating p63. Pathol Res Pract. 2017:213:1119-24.

78. Yanase N, Hayashida M, Kanetaka-Naka Y, Hoshika A, Mizuguchi J. PKC- $\delta$ mediates interferon-a-induced apoptosis through c-Jun NH 2-terminal kinase activation. BMC Cell Biol. 2012;13:7.
79. Li XW, Tuergan M, Abulizi G. Expression of MAPK1 in cervical cancer and effect of MAPK1 gene silencing on epithelialmesenchymal transition, invasion and metastasis. Asian Pac J Trop Med. 2015;8:937-43.

80. Mitra P, Kalailingam P, Tan HB, Thanabalu T. Overexpression of GRB2 enhances epithelial to mesenchymal transition of A549 cells by upregulating SNAIL expression. Cells. 2018;7:97.

81. Garakani K, Shams H, Mofrad MRK. Mechanosensitive conformation of vinculin regulates its binding to MAPK1. Biophys J. 2017;112:1885-93.

82. Cao HY, Xiao CH, Lu HJ, Yu HZ, Hong H, Guo CY, et al. MiR-129 reduces CDDP resistance in gastric cancer cells by inhibiting MAPK3. Eur Rev Med Pharmacol Sci. 2019;23:6478-85.

83. Yang Y, Li XJ, Li P, Guo XT. MicroRNA-145 regulates the proliferation, migration and invasion of human primary colon adenocarcinoma cells by targeting MAPK1. Int J Mol Med. 2018;42:3171-80.

84. Ge J, Yan Q, Wang YJ, Cheng XQ, Song D, Wu C, et al. IL-10 delays the degeneration of intervertebral discs by suppressing the p38 MAPK signaling pathway. Free Radic Biol Med. 2020;147:262-70.

85. Frelin C, Ofran Y, Ruston J, Hayun M, Derdikman Y, Khier Y, et al. Grb2 regulates the proliferation of hematopoietic stem and progenitors cells. Biochim Biophys Acta Mol Cell Res. 2017;1864:2449-59.

86. Rees P, Schoeman JP. Plasma insulin concentrations in hypoglycaemic dogs with Babesia canis rossi infection. Vet Parasitol. 2007;152:60-6.

87. Varshney P, Dey CS. P21-activated kinase 2 (PAK2) regulates glucose uptake and insulin sensitivity in neuronal cells. Mol Cell Endocrinol. 2016;5:50-61.

88. Varshney P, Dey CS. Resveratrol regulates neuronal glucose uptake and insulin sensitivity via P21-activated kinase 2 (PAK2). Biochem Biophys Res Commun. 2017:485:372-8.

\section{Publisher's Note}

Springer Nature remains neutral with regard to jurisdictional claims in published maps and institutional affiliations.
Ready to submit your research? Choose BMC and benefit from:

- fast, convenient online submission

- thorough peer review by experienced researchers in your field

- rapid publication on acceptance

- support for research data, including large and complex data types

- gold Open Access which fosters wider collaboration and increased citations

- maximum visibility for your research: over $100 \mathrm{M}$ website views per year

At BMC, research is always in progress.

Learn more biomedcentral.com/submissions 